\title{
O NOVO LUGAR DO PAI COMO CUIDADOR DA CRIANÇA
}

\author{
Sérgio Luiz Saboya Arruda \\ Professor doutor aposentado do Departamento de Psicologia Médica e Psiquiatria da Faculdade de \\ Ciências Médicas da Universidade Estadual de Campinas (UNICAMP), Campinas SP. \\ Manuela Caroline Ferreira Lima \\ Psicóloga pela UEM. Especialista em Psicoterapias na Infância pela FCM-UNICAMP.
}

\begin{abstract}
Resumo
Atualmente, observa-se um período de transição e de importantes mudanças no que diz respeito à função parental, à paternidade, aos valores e modos de vida, tanto no contexto individual, como no ambiente da família. Nessa conjuntura, é feito um estudo teórico psicológico, com o objetivo de refletir a respeito da evolução das funções do pai em relação aos papéis na família e enquanto cuidador de seus filhos. O papel paterno tem mudado de um patriarcalismo para o de parentalidade, um conceito mais amplo e contemporâneo. O pai pode estar deixando de ter uma posição secundária em relação à mãe, quer na criação e no desenvolvimento emocional dos filhos, quer pelos benefícios advindos quando se envolve afetivamente como cuidador.
\end{abstract}

Palavras-chave: paternidade; relação pai-filho; cuidado da criança.

\section{THE NEW PLACE OF THE FATHER AS CAREGIVER OF THE CHILD}

\begin{abstract}
Currently, there are important changes regarding the parental function, the paternity, the values and the way of life, as much in the individual context as in the environment of the family. It is longed for a theoretical psychological study, with the aim to reflect on the evolution of the paternal function in relation to the roles inside the family. The paternal function has evolved from a patriarchal view to a newer and larger contemporary: conception, a father who also provides support and care by looking after the children. Therefore, the father could be leaving to have a secondary role in relation to the mother. Concerning the education and the emotional development of the child, the emotional father's relationship does have significant benefits to himself, to the growing and development of the child and also to the dynamics of the family
\end{abstract}

Keywords: paternity; father-child relations; child care.

\section{EL NUEVO LUGAR DEL PADRE COMO CUIDADOR DEL NIÑO}

\begin{abstract}
Resumen
Hoy día, nos defrontamos con un período de transición y de cambios importantes en lo que respecta a la función parental, a la paternidad, a los valores y conductas de vida, así en el contexto individual como en el ambiente familiar. En ese encuadre, se hizo un estudio teórico psicológico con el objetivo de reflexionar sobre la evolución de las funciones del padre cuanto a los roles en la familia y cuanto a ser cuidador de sus hijos. El papel paterno ha evoluyido desde un modo patriarcal a uno de parentalidad, un concepto mucho más amplio y contemporáneo. El padre puede estar dejando de tener una posición secundaria a la de la madre, sea por su participación en los cuidados y en el desarrollo emocional de los hijos, sea también por los beneficios consecuentes a su envolvimiento afectivo como cuidador.
\end{abstract}

Palabras clave: paternidad; relaciones padre-hijo; cuidado del niño. 


\section{INTRODUÇÃO}

O papel dos pais, a paternidade e a função paterna são temas menos estudados do que o papel da mãe, a maternidade e a função materna, principalmente quando estes assuntos são associados aos filhos, à educação e ao desenvolvimento emocional das crianças. Além disto, os estudos psicológicos referentes aos pais começaram a ser feitos mais recentemente em comparação com aqueles que dizem respeito às mães.

As demandas do mundo pós-moderno estão propiciando mudanças nas rotinas de homens e mulheres, o que afeta o desempenho de papéis sociais, dentre eles o ser pai. A função paterna não é mais definida pelos parâmetros rígidos que moviam o modo de vida patriarcal, no qual o homem era a cabeça da família e único responsável pelo sustento financeiro. Observa-se, atualmente, um período de transição nos valores e nos modos de vida, tanto individualmente, como no contexto da família.

A contemporaneidade tem proporcionado mudanças socioculturais, que afetam o modo de vida dos indivíduos e, conseqüentemente, seu modo de interagir com o meio em que se inserem. Nessa perspectiva, é importante falar de "papéis", tal como ensina Maisonneuve (1977). Para este autor, cada sociedade é regida por papéis e suas interações. "Papel" é entendido como o agrupamento de normas sociais que dirigem a vida de uma pessoa enquanto um ser social.

Na coletividade, cada pessoa assume um papel ou conjunto de papéis, que se mostram condizentes com os modelos estabelecidos no meio em que se insere. Tais papéis possuem uma função de complementação, ou seja, a conduta de uma pessoa é influenciada pelo comportamento de seus pares. Maisonneuve (1977) enfatiza, dessa maneira, que os papéis possuem características importantes, influenciadas pelas interações entre as pessoas, em relação aos outros indivíduos, e também variam de acordo com a situação ou problema que enfrentam.

A presente pesquisa se caracteriza como um estudo teórico. Foi realizada uma busca, por meio eletrônico, de artigos científicos, periódicos e livros, relacionados com o tema escolhido, isto é, o lugar do pai na família atual. O trabalho foi dividido em duas partes principais. A primeira traçou um panorama histórico sobre a paternidade, de forma a entender como os aspectos sociais 
influenciaram e ainda influenciam as demandas do ser pai nos dias de hoje, culminando em um conceito mais amplo, denominado "parentalidade".

Em seguida, foi abordado o papel do homem enquanto cuidador de seus filhos. Pretendeu-se, assim, refletir sobre os benefícios, tanto para o pai quanto para a criança, de uma participação mais efetiva no dia-a-dia doméstico, exercendo funções tidas anteriormente como exclusivas do universo feminino.

\section{PERSPECTIVA SOCIAL DA PATERNIDADE E DA FAMÍLIA: DO PATRIARCALISMO À PARENTALIDADE}

Para falar do homem enquanto pai, é necessário contextualizá-lo brevemente no principal ambiente em que ele se caracteriza como tal: a família. Ao descreverem o modelo de família presente nos dias atuais, Negreiros e FéresCarneiro (2004) ressaltam a importância dos papéis de gênero, em que o masculino e o feminino são entendidos como construções sócio-históricas e culturais. Acreditam que, atualmente, é possível perceber a convivência simultânea de dois tipos principais de grupos familiares, aos quais denominam de "modelo antigo" e "modelo novo".

O "modelo antigo" é pautado em valores tradicionais, que estão baseados na dicotomia homem-mulher, sendo que a função social de um automaticamente é oposta à do outro. Percebe-se, também, uma situação de hierarquia em termos de poder, uma vez que a mulher e a criança devem sujeitar-se à autoridade do homem (Negreiros \& Féres-Carneiro, 2004). Sendo assim, há uma delimitação rígida dos papéis: ao homem cabem obrigações relacionadas com a provisão financeira e com a proteção de seus familiares. À mulher cabe a missão de gerar e de promover cuidados, dentro das demandas domésticas de seu dia-a-dia.

Verdi (2007) lembra que o "modelo antigo" de família consagra-se, ainda, como dominante, embora esta situação esteja sendo revertida. Apesar disso, percebe-se a formação cada vez mais expressiva de agrupamentos mais complexos (famílias recasadas, homoparentais, monoparentais, etc.). Este autor explica que isso ocorre porque o conceito de família já não é mais explicado por meros laços biológicos. Prevalecem, hoje em dia, os aspectos subjetivos, como o vínculo e a identificação com outras pessoas, fatores esses que são a base dos laços afetivos.

Passos (2007) ressalta que é mais indicado falar de estruturas, considerando-se que atualmente a família se organiza de formas bastante 
variadas. Vive-se uma época de individualismo extremo, e os valores que caracterizam esse modo de vida têm influência sobre a construção da parentalidade e, conseqüentemente, sobre a formação da subjetividade dos filhos.

Com relação ao "modelo novo" de grupos familiares, Negreiros e FéresCarneiro (2004) apontam que se abre caminho para que as mulheres se descubram capazes de colaborar no sustento financeiro de seu lar. Podemos perceber, assim, uma difusão nos papéis masculino e feminino, que repercutem, conseqüentemente, nas funções materna e paterna. No entanto, os homens têm dificuldade nesse tipo de realização, por ainda se considerarem como meros coadjuvantes das mulheres, por acreditarem que a mãe faz melhor que eles, já que culturalmente elas teriam sido mais preparadas para desenvolver essa função. Por esta razão, é possível afirmar que os homens ainda não estão seguros em termos de estabelecer um novo lugar para si no universo doméstico e em relação ao papel de cuidadores.

Brasileiro, Jablonski e Féres-Carneiro (2002) mostram que essa realidade pode ser mudada, se o homem tiver oportunidade de ficar com seus filhos, sem que haja intromissões na interação entre eles, e a mulher aprenda a delegar tarefas ao pai, no que se refere ao trabalho direcionado à criança.

Ao se ter um filho, a realidade muda tanto para mulheres, quanto para os homens, posto que ambos se deparam com a necessidade de assumirem novos papéis. Freitas, Coelho e Silva (2007) citaram, especialmente, a situação de gravidez e gestação, e mostraram, em sua pesquisa, como as noções de paternidade e de maternidade são construídas histórica e culturalmente: "A reprodução social dos modelos masculino e feminino tem a sua base na maternagem (mothering), termo que significa cuidados de mãe, cujo valor cultural na reprodução da masculinidade tem um sentido ideológico na produção das desigualdades entre os sexos" (p. 138).

Perucchi e Beirão (2007) apresentam a maternidade e suas funções como um processo construído socialmente, sendo entendido como uma característica "naturalizada", inerente à mulher. Em contrapartida, a paternidade é algo estranho, distante, já que os homens não engravidam, não amamentam e, por conseguinte, não formam um vínculo tão forte com o filho, como o estabelecido pela mulher desde a concepção. 
Segundo Bustamante e Trad (2005), a naturalização da função da mulher enquanto cuidadora é compreensível, dada a construção histórica dos papéis sociais e da estrutura familiar. Silva (2007) considera a paternidade "como uma construção histórica social e cultural que sofre transformações de sentido e significado em diferentes contextos culturais, os quais são passados entre as gerações" (p. 55). Em muitos grupos familiares, a paternidade ainda é exercida de maneira estereotipada, presa às amarras das questões de gênero, das diferenças biológicas existentes entre homens e mulheres.

Apesar disso, Bustamante e Trad (2005) mostram uma realidade inédita, cujas facetas ainda inspiram curiosidade: uma nova expectativa social, relacionada ao homem. Espera-se que ele seja o "novo pai", aquele que demonstra, de forma mais clara, afeto pelas crianças e que estabeleça uma relação mais igualitária com a mulher, o que implica assumir parte das tarefas domésticas e dos cuidados com os filhos. O relacionamento igualitário é entendido de acordo com o que escrevem Brasileiro e colaboradores (2002):

os cônjuges buscam uma participação equilibrada tanto no trabalho doméstico e familiar quanto na contribuição econômica para a subsistência da família. Isto não significa uma divisão de $50 \%$ para cada cônjuge, e sim uma divisão onde haja, além da equivalência na participação de cada um, consciências e concordâncias mútuas ( $p$. 19).

Winnicott (2001), na época de suas pesquisas, já reconheceu a vontade de alguns pais terem uma participação mais ativa na vida dos filhos. Isso pode ser percebido quando escreve sobre a mãe:

Penso que nesta altura dos acontecimentos ela tem poucas possibilidades de entender como é que alguns homens podem invejar mulheres - invejá-las porque ficam em casa, atravancadas de afazeres domésticos e metidas na mais maravilhosa e deslumbrante bagunça com bebês e crianças pequenas (p. 82).

Grossi (2007) acredita que, atualmente, falar de "maternidade" ou "paternidade" não expressa suficientemente a natureza do cuidar dos filhos. Há uma extensão desses papéis, que culminam em um processo único, denominado "parentalidade", já que as funções tidas como masculinas e femininas passaram a ser realizadas tanto pelos homens como pelas mulheres. Verdi (2007) também considera o conceito de "parentalidade". Nessa perspectiva, este autor valoriza a participação efetiva dos pais no desenvolvimento das crianças, já que atualmente o ideal de paternidade visa a um homem que participe da educação de seus filhos, com amor, autoridade, respeito, preocupação e senso de justiça. 
Para ilustrar esses aspectos, é importante citar o trabalho de Perucchi e Beirão (2007), autoras que discutem a paternidade na visão de mães chefes de família, que por inúmeras razões acabam assumindo a sobrecarga das funções materna e paterna. Além de terem seu próprio trabalho e de cuidarem do sustento dos filhos, essas mães participam, em tempo integral e de forma dedicada, de várias atividades das crianças, como lazer, tempo livre, auxílio nas tarefas escolares, entre outras. A expectativa que elas possuem em relação à paternidade é baseada em funções divididas pelos critérios de gênero, pautadas nas diferenças sexuais e biológicas características da visão patriarcal. Para elas, é dever do pai participar de forma ativa da educação de seus filhos, bem como estabelecer regras e limites de comportamento. Quanto à provisão financeira, essas mães consideram que esta é uma função que pode ser exercida por ambos os membros do casal parental.

Apesar de o individualismo permear os valores e os modos de vida atuais, Passos (2007) aponta particularidades interessantes no grupo familiar. O ser humano está mais voltado para sua individualidade e seus desejos, embora a vontade de ter filhos continue presente. É preciso ressaltar, porém, que o modo de exercer a maternidade e a paternidade é diferente. Ter filhos não expressa mais uma mudança extrema, na qual se anula a vida para se garantir o bemestar das crianças. Atualmente o anseio por filhos expressa um sonho, ter um prolongamento de si mesmo e usufruir da alegria que essas crianças podem proporcionar.

Outro aspecto que influencia a vivência da paternidade é a relação que o homem viveu com o seu próprio pai. Freitas, Coelho e Silva (2007) afirmam que os homens contemporâneos, em sua maioria, conviveram com um pai distante e pouco envolvido afetivamente, o que influencia de forma significativa a construção de sua masculinidade e, conseqüentemente, a construção do modelo de paternidade que exercerá.

Wang, Jablonski e Magalhães (2006) explicam que isso ocorre devido ao processo de socialização em que o homem se insere desde o nascimento, ao vivenciar os estereótipos de gênero nas relações parentais e na educação que recebe. Por esta razão, o modelo de virilidade que constrói é pautado na desvalorização de suas necessidades afetivas, em detrimento de uma visão social que impõe que ele seja forte e independente. No entanto, à medida que esse menino cresce, tem a oportunidade de se defrontar com novas representações 
que, somadas às antigas, determinarão a realização de papéis que lhe serão atribuídos futuramente (pai, marido, trabalhador...).

A situação econômica presente é uma dessas novas situações. Com o desemprego crescente e o elevado custo de vida, está cada vez mais difícil para o homem manter o lar e a família com os seus próprios proventos, o que torna o salário da mulher indispensável. No ambiente de trabalho, ele tem a percepção que as mulheres executam as tarefas em igualdade de condições ou até melhor que ele (Wang, Jablonski \& Magalhães, 2006).

Por esta razão, ao repensar seu lugar e função enquanto indivíduo do gênero masculino na sociedade, o homem tem a oportunidade de refletir sobre suas necessidades individuais. Isso abre caminhos, por exemplo, para dedicar-se não somente à subsistência da casa, como também ao desejo de participar, mais diretamente, da construção de um ambiente de bem-estar em sua família.

Negreiros e Féres-Carneiro (2004) refletem sobre as representações sociais. Dizem que, apesar de aparentemente haver um modelo novo, os costumes antigos ainda se mostram presentes na coletividade. Brasileiro e colaboradores (2002) explicam que, para os pais e mães da contemporaneidade, é difícil colocar em prática os novos paradigmas de atuação, uma vez que a visão antiga ainda restringe a vontade individual. Ao mesmo tempo em que se impulsiona o homem a ir para casa e a mulher a ir trabalhar fora, há contradições como a diferenciação do trabalho e do salário por gênero. Isso acaba por contribuir para manter a "tradicionalização" dos papéis sociais.

\section{O PAPEL DO PAI ENQUANTO CUIDADOR E SUA INFLUÊNCIA NO DESENVOLVIMENTO DA CRIANÇA}

Sutter e Bucher-Maluschke (2008), em seu estudo sobre o pai, constataram uma interessante realidade: apesar de a mulher se constituir, ainda hoje, como a principal cuidadora, há homens que se esforçam para participar do desenvolvimento dos filhos, envolvendo-se, portanto, no cuidado direcionado às crianças. Essa nova aquisição de papéis é chamada de "paternidade participativa", que se caracteriza pelo envolvimento no dia-a-dia dos filhos, em atividades de educação, lazer, alimentação e higiene. Todavia, é importante ressaltar que a qualidade e o tipo de envolvimento paterno variam de acordo com a disponibilidade pessoal e de tempo do pai, considerando que, em seu imaginário social, ele ainda está em busca da definição de seu espaço. 
O trabalho de Prado, Piovanotti e Vieira (2007) ilustra essa questão. Eles fizeram uma pesquisa na cidade de Florianópolis - SC, com o objetivo de averiguar a percepção que o casal parental possui em relação aos cuidados dedicados pelo pai. Para isso, foram utilizadas escalas de estilo paterno, com o objetivo de identificar padrões sociais relacionados com a paternidade e diferenças entre pais e mães sobre a percepção do comportamento paterno em termos reais e ideais. Esses autores averiguaram que, em termos de interação com os filhos, homens e mulheres têm opiniões semelhantes sobre o ideal de paternidade, considerando-o como aspecto fundamental para o desenvolvimento da criança. No entanto, a prática é divergente, já que, nas famílias pesquisadas, revelou-se que os homens consideram fazer o suficiente pelos filhos, enquanto as mulheres acreditam que eles poderiam ter uma participação mais efetiva. Foram considerados, sob este parâmetro, aspectos como didática, tempo disponível para as crianças, interação social e disciplina, sendo que os limites compõem a área considerada de maior participação do pai.

Para Freitas, Coelho e Silva (2007), essa possibilidade de dedicação paterna pode agregar muitos benefícios ao filho, visto que um pai devotado, que lhe dispensa cuidados, carinho e atenção, pode contribuir bastante para seu desenvolvimento. Verdi (2007) esclarece que a importância da presença do pai se deve ao fato de que ajuda a construir, ao lado da atenção dedicada pela mãe, os fundamentos da subjetividade da criança: "Da experiência de acolhimento resulta uma confiança básica para estar no mundo, da interdição, o reconhecimento do outro e a condição para a autonomia" (p. 13).

Sutter e Bucher-Maluschke (2008) mostram que o interessante no cuidado paterno é que os homens procuram tratar a paternidade de forma diferenciada, não simplesmente repetindo tudo aquilo que a mulher faz. Desse modo, eles consideram sua dedicação ao filho como algo "mais lúdico, mais prático e com mais facilidade para frustrar o filho" (p. 81).

Winnicott (1982) fala da realidade de pessoas casadas, do quanto a vida da criança e delas próprias é enriquecida quando o casal parental compartilha aspectos aparentemente banais de seu dia-a-dia, como por exemplo, a hora do banho. No entanto, ressalta que o pai não deve ter a pretensão de substituir a mãe, mas auxiliá-la no que for preciso, de forma que ela se sinta tranqüila e feliz no desempenho de sua função. Nessas condições, ela se sentirá melhor e mais preparada para exercer um cuidado mais dedicado ao bebê e, portanto, estará 
disponível para suprir suas necessidades, sem se sentir sobrecarregada ao fazêlo.

Winnicott (1982) considera que a atitude da mãe possui uma influência forte na determinação do tipo de relação que o homem estabelecerá com seu bebê ou criança. Já na época em que escreveu este texto, este psicanalista apontava os problemas que poderiam intervir na formação de vínculo entre pai e filho: (1) ao trabalhar, o pai poderia ficar fora de casa por um tempo excessivo, e chegar quando a criança estivesse dormindo; (2) a mãe, por não saber como e quando solicitar que o marido a ajude, o que pode tornar o homem mais distante da realidade cotidiana de seu lar. Tais dificuldades ainda se mostram nos dias de hoje, mas com um agravante: se a mulher trabalha fora, é imprescindível que o homem (ou outra pessoa) a ajude, mas como fazê-lo? O que cabe a cada um?

Ainda em relação ao desempenho do homem enquanto pai, destaca-se que há mulheres que mostram certa ambivalência em relação à maior participação do pai, por razões subjetivas como a competência do seu marido como um cuidador. Isto é caracterizado pelo temor da perda de controle sobre a maternagem, território ainda hoje dominado pelas mulheres, domínio este no qual sempre exercitaram um poder significativo. Também há insegurança na redefinição dos papéis sociais, o que significa mudanças nos padrões para o trabalho doméstico, bem como as maneiras utilizadas para assegurar 0 crescimento e pleno desenvolvimento orgânico e psíquico da criança. Por conseguinte, o nível de participação dos pais na vida dos filhos é determinado pela extensão que as mulheres aceitam essa aproximação.

Quando o pai se mostra empático e encorajador, fornece subsídios à mãe para que ela seja mais paciente, flexível, emocionalmente disponível e, por essa razão, mais eficiente. Com a melhora da relação mãe-criança, é possível vislumbrar um desenvolvimento mais qualitativo para a criança. Em contrapartida, o apoio da mãe para que o pai tenha uma participação mais efetiva é fundamental, já que pode motivar o homem a exercer melhor as atividades relacionadas com a paternagem. Assim, cabe ao pai:

dar à mãe o apoio moral, ser um esteio para sua autoridade, um ser humano que sustenta a lei e a ordem que a mãe implanta na vida da criança. Ele não precisa estar presente o tempo todo para cumprir essa missão, mas tem que aparecer com bastante freqüência para que a criança sinta que o pai é um ser vivo e real (Winnicott, 1982, p. 129). 
Winnicott (1990) ressalta a importância, para o desenvolvimento da criança, de esta poder contar com um ambiente doméstico, principalmente no período anterior à latência e posterior à capacidade de estabelecer relacionamentos interpessoais. Assim, acredita que "o ambiente tem que ser suficientemente bom, e precisa ser mantido" (p. 176). Do mesmo modo, discorre sobre os aspectos que influenciam a integração e o assentamento da psique e do corpo, nos quais o ambiente e os cuidados físicos têm tarefa essencial, já que são realizados como expressões de amor. Nesse ponto, Winnicott explica que se o cuidado é bom, não importa se é a mãe ou outra pessoa que o emprega. No entanto, não é apropriado para o bebê que haja variação excessiva de tais técnicas, porque isso pode levá-lo à confusão.

Para Winnicott (1990), a família surge na vida da criança quando ela se desenvolve a ponto de perceber a existência de três pessoas, ela mesma e seus pais. Esse é o ponto de partida para que ela possa se estruturar e ser capaz de estabelecer relacionamentos cada vez mais complexos. Outra função importante que os pais possuem é propiciar ao filho a possibilidade de se desenvolver desde a concepção até o fim da adolescência. Winnicott acredita que a paternidade participativa está relacionada positivamente com a competência social, a maturidade e a capacidade da criança para relacionar-se com o outro.

Winnicott (2001) atribui grande importância ao que chama de ambiente, já que o indivíduo, a partir das condições que o cercam, pode seguir um caminho rumo ao desenvolvimento emocional e à independência. "Existe algo em ter um bebê (até na preparação em adotar um bebê) que altera os pais. Eles passam a estar orientados para a tarefa especial. Quero dar a isso um nome e por isso chamei-Ihe Preocupação Maternal Primária" (p. 150).

Goetz e Vieira (2007) realizaram uma pesquisa em que compararam as percepções de crianças que são filhos de pais casados com as de filhos de pais separados em relação ao envolvimento paterno. Concluíram que, para as crianças em ambas as situações, é importante que o pai se mostre capaz de realizar cuidados e atividades voltadas para a diversão e brincadeiras. É importante frisar, também, que essas crianças estudadas esperavam da mãe atitudes semelhantes.

Esses autores colocam que o cuidado dedicado aos filhos é percebido com uma diferença gritante pelas crianças. Quando o pai vive com a mãe, é mais fácil que ele se mostre presente e se aproxime mais do ideal de parentalidade 
concebido por elas (o cuidado real dedicado pela mãe, mesmo que esta não compartilhe as tarefas com o pai no convívio). Quando os pais são separados, o homem tende a se manter afastado por vários motivos, desde conflitos com a mulher até questões culturais. "Quando as relações parentais são construtivas podem ter influência positiva, mesmo na separação conjugal, ensinando às crianças valiosas lições pelas expressões de conflitos e negociações" (Goetz \& Vieira, 2007, p. 84).

Winnicott (1982) aponta um aspecto interessante, o das brincadeiras infantis, nas quais as crianças imitam pai e mãe, no que se refere à forma em que estas enxergam o desempenho de suas tarefas. Descreve o cuidado materno e as demandas domésticas como algo particular do universo feminino, um lugar onde as crianças se encontram inseridas desde o momento em que nascem e, por esta razão, estão familiarizadas. Já o pai, seu trabalho e as suas atividades de lazer representam um olhar para fora, para um mundo novo, uma vivência externalizada.

Igualmente, é fundamental que haja, independentemente de o pai viver ou não na mesma casa, a negociação entre os pais em relação às condutas destinadas ao desenvolvimento infantil. Em vista disto, é preciso que os conflitos interparentais se mantenham sob controle, de modo que seja possível, para a criança, estabelecer níveis satisfatórios de interação com ambos os pais.

O cuidado mostra-se importante tanto para o homem, quanto para o bebê. Ao se ocupar da criança, o pai cria uma nova oportunidade de se desenvolver enquanto indivíduo, uma vez que, ao dar preferência às questões do lar, torna-se possível o estabelecimento de vínculo afetivo.

Em estudo sobre a participação do pai em famílias inglesas, O 'Brien (2005) mostra que as pesquisas da área da psicologia, tradicionalmente, baseiam-se muito na opinião da mãe e não verificam o comportamento paterno. Essa realidade dificulta a confirmação da hipótese de que o pai sozinho, isto é, sem a influência materna, tem alguma importância em relação ao desenvolvimento do filho. Além disso, esta autora considera não haver qualquer tipo de controle do nível e da qualidade do envolvimento materno experimentado pelas crianças, o que impede a percepção da real contribuição da maternagem e da paternagem no desenvolvimento da criança.

Por esta razão, Goetz e Vieira, (2007) afirmam ser importante considerar, em qualquer investigação sobre o tema, a visão que as crianças têm do que são 
a função paterna e materna, de acordo com seu entendimento, necessidades e desejos.

\section{CONSIDERAÇÕES FINAIS}

O presente estudo procurou discutir alguns aspectos interessantes sobre 0 ser pai e como o homem chega ao desempenho desta função, nos dias de hoje. Para isso, é preciso levar em consideração aspectos sócio-econômicos e culturais, que possuem influências marcantes na execução das demandas de qualquer papel social. Nesse sentido, a partir do atual conceito de parentalidade, em substituição ao modelo de patriarcalismo, foram comentados aspectos como o relacionamento emocional do gênero masculino com seus familiares (genitores, cônjuge, filhos), a correspondente divisão e interação dos papéis parentais mantidos por eles e a tentativa de adaptação da função paterna em um mundo no qual a criança não pode mais contar com o cuidado exclusivo da mãe.

Com a atual ordem sócio-econômico-cultural, percebe-se que pai e mãe possuem necessidades e desejos que, em muitos casos, permitem o estabelecimento de uma parceria, dividindo os encargos característicos da parentalidade. Com a saída da mulher do ambiente exclusivamente doméstico, torna-se possível a redescoberta, pelo homem, do que é ser pai. O mesmo passa a sentir-se mais estimulado a refletir sobre a melhor forma de ajudar o filho a desenvolver suas potencialidades.

No entanto, não é possível chamar essa participação masculina de igualitária. A sociedade que pressiona o homem a ser amoroso, prestativo e cuidadoso em relação aos filhos é a mesma que o discrimina, se ele tiver que sair do trabalho para participar de uma reunião de escola, por exemplo. Tal tipo de tarefa ainda cabe, de forma dominante, à mulher, e isso pode ser um fardo para ela, visto que muitas vezes se vê tolhida em suas vontades e autonomia, percebendo-se prejudicada em sua evolução profissional. O casal parental, muitas vezes, busca o equilíbrio, mesmo que eles não vivam juntos. É possível ver isso em esforços como a lei que regulamenta a guarda compartilhada para casais separados. Porém, as contradições sociais muitas vezes se tornam percalços extremamente difíceis a serem superados.

Sobre os textos estudados, é importante ressaltar alguns aspectos. Todos mostraram o interesse que o tema "pai" tem despertado na comunidade acadêmica. Ressaltam os aspectos positivos, como o envolvimento no cuidado 
com os filhos e nas tarefas domésticas. Tais fatores tiveram como conseqüência a melhora da relação do homem com a mãe da criança, quando mantinham um relacionamento conjugal. Também há uma convivência maior com o filho, o que proporcionou ao pai a possibilidade de conhecê-lo melhor, conviver com ele e sentir-se mais útil, apesar de ele próprio se definir como mero coadjuvante da mulher.

É possível perceber, nos artigos que são a base dessa pesquisa, que muito se escreveu a respeito da mudança nos papéis de gênero, no fim da dicotomia masculino-feminino, e na necessidade que os homens têm de descobrir o seu lugar na vida em família, escapando dos limites dos estereótipos sexuais. Porém, pouco se falou do impacto dessas mudanças na vida das crianças. Não obstante, houve exceções a esta situação, como o artigo de Goetz e Vieira (2007), que discorreram sobre a percepção de crianças sobre o cuidado que recebem de seus pais. Isso conferiu à segunda parte do artigo um status de desafio, devido à dificuldade de encontrar material na literatura que tratasse, de forma mais enfática e detalhada, a influência do cuidado paterno no desenvolvimento emocional da criança.

Diante disso, ficamos com as palavras de Grossi (2007), que aponta a importância, para as crianças, do estabelecimento de um vínculo afetivo também com o pai. Mesmo em famílias em que, por diversos motivos, não há um pai presente, é preciso que haja alguém que possa desempenhar esse papel.

Sob essa perspectiva, recebe grande destaque o trabalho de Winnicott. Há certo pioneirismo em suas idéias, pois ainda que de forma tímida (tendo em consideração que, em sua época, a relação mãe-bebê recebeu maior destaque em comparação à díade pai-filho), este psicanalista chegou a mostrar a importância da presença masculina tanto para a mulher (na função de suporte, de apoio), quanto para a criança (aspectos inerentes ao desenvolvimento).

É interessante, nesse sentido, apontar a realidade de um país como a Suécia. Essa nação destaca-se como a primeira a transformar, em 1974, a licença maternidade em um novo benefício remunerado para ambos os pais (Faria, 2002). Tal medida permitiu uma divisão mais igualitária entre homens e mulheres nos cuidados com a casa e com os filhos. Sob essa perspectiva, são concedidos outros benefícios, como licenças mais longas e flexíveis, visando a suprir as necessidades familiares. 
Infelizmente, em muitos países que são regidos por um sistema capitalista, apesar de se fazer necessária a presença de ambos os pais no mercado de trabalho, não se percebe um apoio eficaz ao exercício das funções parentais sem prejuízo aos ganhos financeiros da família. Nessa conjuntura, pode-se falar da realidade brasileira. Uma das medidas realizadas pelo governo é a ampliação da licença-maternidade de 4 para 6 meses, com o objetivo de prolongar o tempo de lactação ao seio. No entanto, essa medida não está sendo bem vista pelas empresas, que apesar de receberem compensações como descontos em impostos, não querem treinar pessoas para ocupar o lugar das mães durante a licença-maternidade. Outro ponto de resistência vem das próprias mulheres.

Considero que o aumento da licença não protege sozinha a relação mãe-filho, pois, ao final desse período, teremos ainda um mesmo bebê e uma mãe que, possivelmente, não disporá de equipamentos urbanos públicos ou mantidos pelos empresários que garantam um lugar digno onde manterem seus filhos. Além do que, falarmos em soluções definitivas é incluir também os cuidados e a atenção dos pais, que, também trabalhadores, poderão pactuar os cuidados com os filhos e serem responsáveis na sua paternidade" (Dultra, 2008, p. 1)

Nesse sentido, as mulheres temem por seus empregos e sua empregabilidade, uma vez que acreditam que um afastamento tão grande pode afetar sua carreira para o resto da vida. Dultra (2008) considera, ainda, que a possibilidade de engravidar pode ser um fator a mais a dificultar o acesso da mulher ao mercado de trabalho.

Para pesquisas futuras, ressalta-se a necessidade de estudos que abarquem outros temas afins, como a relação pai-filho e a subjetividade do homem enquanto pai, bem como o desempenho de suas tarefas em cada fase do desenvolvimento da criança. É preciso, no entanto, que haja um olhar mais dedicado ao homem e ao seu filho, e também ao que ocorre entre eles, sem interrupções. Certamente essa é uma tarefa complexa, porém necessária para promover estudos ulteriores nas áreas de psicologia e do desenvolvimento.

\section{REFERÊNCIAS}

Brasileiro, R. de F., Jablonski, B., \& Féres-Carneiro, T. (2002). Papéis de gênero, transição para a paternalidade e a questão da tradicionalização. Psico, 33(2), 289-310. 
Bustamante, V., \& Trad, L. A. B. (2005). Participação paterna no cuidado de crianças pequenas: Um estudo etnográfico com famílias de camadas populares. Cad. Saúde Pública, 21(6), 1865-1874.

Dultra, E. (2008). Licença-maternidade: Um direito da mãe e do pai (Entrevista). IHU Online - Revista do Instituto Humanitas Unisinos. Disponível em: http://www.unisinos.br/ihu/index.php?option=com noticias\&Itemid $=18 \&$ tas $\mathrm{k}=$ detalhe\&id=15130. Acesso: 12 jun. 2009.

Freitas, W. de M. F., Coelho, E. de A. C., \& Silva, A. T. M. C. da (2007). Sentir-se pai: A vivência masculina sob o olhar de gênero. Cad. Saúde Pública, 23(1), 137-145.

Faria, C. A. P. (2002). Entre marido e mulher, o Estado mete a colher: Reconfigurando a divisão do trabalho doméstico na Suécia. Revista Brasileira de Ciências Sociais, 17(48), 173-231.

Goetz, E. R., \& Vieira, M. L. (2007). Diferenças nas percepções de crianças sobre cuidado parental real e ideal quando pais vivem juntos ou separados. Psicologia: Reflexão e Crítica, 21(1), 83-90.

Grossi, M. P. (2007). O pai não está desaparecendo: o que temos é uma transformação de papéis (Entrevista Ainda precisamos de pai? Da paternidade para parentalidade). IHU Online - Revista do Instituto Humanitas Unisinos, 230, 4-7.

Maisonneuve, J. (1977). Papéis e conflitos de papel. In J. Maisonneuve, Introdução à psicossociologia (pp. 60-75). São Paulo: Companhia Editora Nacional.

Negreiros, T. C. de G. M., \& Féres-Carneiro, T. (2004). Masculino e feminino na família contemporânea. Estudos e Pesquisas em Psicologia, 4(1), 34-45.

O'Brien, M. (2005). Shared caring: Bringing fathers into the frame. EOC Working Paper Series. Recuperado em 10 de janeiro de 2009 de: http://www.uea.ac.uk/polopoly fs/1.73363!shared caring wp18.pdf.

Passos, M. C. (2007). A constituição dos laços na família em tempos de individualismo. Revista Mental, V(9), 117-130.

Prado, A. B., Piovanotti, M. R. A., \& Vieira, M. L. (2007). Concepções de pais e mães sobre comportamento paterno real e ideal. Psicologia em Estudo, $12(1), 41-50$. 
Perucchi, J., \& Beirão, A. M. (2007). Novos arranjos familiares: Paternidade, parentalidade e relações de gênero sob o olhar de mulheres chefes de família. Psicologia Clínica, 19(2), 57-69.

Silva, M. M. V. de A. (2007). O processo histórico de construção das concepções de paternidade. In J. L. Pereira, C. Fanelli, R. C. Pereira \& S. Rios (orgs.), A sexualidade na adolescência no novo milênio (pp. 54-65). Rio de Janeiro: Universidade Federal do Rio de Janeiro, Pró-reitoria de Extensão.

Sutter, C., \& Bucher-Maluschke, J. S. N. F. (2008). Pais que cuidam dos filhos: A vivência masculina na paternidade participativa. Psico, 39(1), pp. 74-82.

Wang, M.-L., Jablonski, B., \& Magalhães, A. S. (2006). Identidades masculinas: Limites e possibilidades. Psicologia em Revista, 12(19), 54-65.

Winnicott, D. W. (1982). E o pai? In D. W. Winnicott, A criança e o seu mundo (6a ed., pp. 127-133). Rio de Janeiro: LTC Editora.

Winnicott, D. W. (1990). O ambiente. In D. W. Winnicott, Natureza Humana (pp. 173-180). Rio de Janeiro: Imago Editora.

Winnicott, D. W. (1990). Família. In D. W. Winnicott, Natureza Humana (pp. 57). Rio de Janeiro: Imago Editora.

Winnicott, D. W. (2001). Conversando com os pais (2a ed.). São Paulo: Martins Fontes.

Verdi, M. S. (2007). Os papéis de pai e mãe são muito relevantes (Entrevista Ainda precisamos de pai? Da paternidade para parentalidade). IHU Online Revista do Instituto Humanitas Unisinos, 230, p. 12-15.

Contato: saboya@unicamp.br, manuelaf001@gmail.com

Recebido em: 14/10/2013

Revisado em: 27/11/2013

Aceito em: 05/12/2013 